\title{
Benefits and drawbacks of applied direct currents for soil improvement via carbonate mineralization
}

\author{
Dimitrios Terzis ${ }^{1 *}$, Patrick Hicher $^{1}$, and Lyesse Laloui ${ }^{1}$ \\ ${ }^{1}$ Swiss Federal Institute of Technology Lausanne (EPFL), Soil Mechanics Laboratory, EPFL ENAC IIC LMS Station 18 CH-1015, \\ Lausanne, Switzerland
}

\begin{abstract}
The study presented herein adopts a new vision of the processes involved in carbonate mineralization induced by MICP from an electrochemical and crystal growth perspective. More precisely a specific line of focus refers to the species involved in the bio-chemical reactions and especially their net particle charge. By altering electro-chemical conditions via the application of direct electric currents, we observe distinctive trends related to: (i) overall reaction efficiency; (ii) carbonate mineralization/dissolution and (iii) spatial distribution of precipitates. The study introduces the concept of EA-MICP which stands for Electrically Assisted MICP as a means of improving the efficiency of soil bio-consolidation and overcoming various challenges which were previously reported in conventional MICP-based works. Results reveal both the detrimental and highly beneficial role that electric currents can hold in the complex, reactive and transport processes involved. An interesting finding is the "doped" morphology of calcite crystals, precipitated under electric fields, validated by microstructural observations.
\end{abstract}

\section{Introduction}

The present study aims to shed light on the critical role applied Electrokinetics (EKs) can hold in MICP. We postulate that the reactive solutions involved in MICP (rich in microbes, urea and calcium) represent electrolytes and therefore the electrically induced flow of solutes would impact significantly the fate and efficiency of the process to consolidate porous media via the formation of stable, $\mathrm{CaCO}_{3}$ minerals. Applying electric fields to soils have attracted much attention in the geotechnical field, mainly at laboratory scale, for soil remediation applications (Cardoso and Santos 2013, Citeau et al. 2015, Gingine and Cardoso 2019). Applied EKs enhance electrical motion forces that are effective in distributing either dissolved ions, charged particles or even organic ones. The most efficient electrically induced motion force is electromigration of dissolved ions where the electrical force $\mathbf{F}=q \mathbf{E}$, with q being the charge of the considered species and $\mathbf{E}$ the electric field across the specimen, distributes the ions according to the electric potential distribution. Also, electrophoresis applies on particles or large molecules (typically bacteria) that possess a charged surface due to their polarization under the applied electric field. Previous studies have attempted to introduce electric fields for the application of MICP. More precisely, Keykha et al (2012, 2015) conducted experiments of applied electric currents to Pasteurii bacteria and reported the dependence of electrophoretic mobility of the microorganisms, related to their zeta potential, on the $\mathrm{pH}$ (which increases at the cathode and decreases at the anode) as well as the possibility to enhance the transport rate throughout sandy clay specimens by increasing the applied current (Keykha et al 2015). However, the overall effects of the electric field on the microbial communities remain to be clearly understood (Kim et al 2010). Other findings relate to the injection of calcium ions at the anode and carbonate ions originating from microbially hydrolysed urea at the cathode which results into a good rate of calcification throughout soft clay (kaolinite) by means of EKs transport (electromigration and electroosmosis) of the reactive species (Keykha et al 2014). In addition, EKs also seem to be a promising way of removing ammonium ions which can potentially become a source of environmental contamination (Keykha et al 2017). The present study focuses on the potentially detrimental and beneficial effects of applied EKs to suggest an efficient EA-MICP approach.

\section{Materials and methods}

The study investigates alternative $\mathrm{Ca}^{2+}$ sources and investigates their efficiency as reactive species under applied Direct Current (DC). The vast majority of MICP studies utilize $\mathrm{CaCl}_{2}$ due to its relatively lower price, availability from synthetic routes and high solubility compared to alternative sources (Terzis and Laloui, 2019a). $\mathrm{CaCl}_{2}$ is a purely inorganic salt which displays well known electrolysis reactions that are herein understood with respect to its influence over the microbial activity. With $\mathrm{CaCl}_{2}$ used as a calcium source, $\mathrm{Cl}^{-}$anions are the preferential species that undergoes oxidative reaction at the anode, as follows:

Corresponding author: dimitrios.terzis@epfl.ch 


\section{(1) $2 \mathrm{Cl} \rightarrow \mathrm{Cl}_{2}(l)+2 e$}

due to local low $\mathrm{pH}$ conditions. Active chlorine reacts with water to produce hypochlorous acid according to the following reaction:

$$
\text { (2) } \mathrm{Cl}_{2}(l)+\mathrm{H}_{2} \mathrm{O} \rightarrow \mathrm{HOCl}+\mathrm{H}^{+}+\mathrm{Cl}
$$

which is in equilibrium with hypochlorite at $\mathrm{pH}$ around 7.5. Among all oxidants, hypochlorite is mainly known for its powerful disinfecting activity, being the main agent of bleach water. Amino and thiol groups of proteins are particularly sensitive to the electrophilic attack of the latter oxidant (S. Fukuzaki 2006). Even germs that are protected by their plasma membrane drastically suffer from the action of hypochlorite acid that is able to penetrate into the lipid bilayer of living cells and destroy them. We introduce Sporosarcina Pasteurii cells in the sand column experiments previously reported in Terzis and Laloui (2019b). Electrical conductivity (EC) analysis coupled with Ion Chromatography measurements to detect ionic species $\left(\mathrm{Ca}^{2+}\right.$ and $\left.\mathrm{NH}_{4}^{+}\right)$and monitor the evolution of MICP under applied EKs by comparing it with conventional MICP, i.e. bio-cementation under no applied field. Three alternative $\mathrm{Ca}^{2+}$ sources (Table 1) are provided to the system under no and applied electric field. These are calcium chloride, calcium acetate and calcium lactate.

Table 1. Calcium sources used in the study of EA-MICP.

\begin{tabular}{|c|c|}
\hline $\mathbf{C a}^{2+}$ source & $\begin{array}{c}\text { Solubility } \\
\left(\mathrm{g} / 100 \mathrm{ml} \text { at } 20^{\circ} \mathrm{C}\right)\end{array}$ \\
\hline $\mathrm{CaCl}_{2}$ & 74.5 \\
\hline $\mathrm{Ca}\left(\mathrm{C}_{2} \mathrm{H}_{3} \mathrm{O}_{2}\right)_{2}$ & 34.7 \\
\hline $\mathrm{CaL}_{2}$ & 4.08 \\
\hline
\end{tabular}

Direct currents in column experiments are applied in the setup shown in Figure 1. The mass of sand in each column is $170 \mathrm{~g}$ in $100 \mathrm{~cm}^{3}$ columns at a void ratio of approximately 0.4 . The concentration of the $\mathrm{CaL}_{2}$ was $0.25 \mathrm{M}$ and that of $\mathrm{Ca}\left(\mathrm{C}_{2} \mathrm{H}_{3} \mathrm{O}_{2}\right)_{2}$ was $0.5 \mathrm{M}$. A sample treated purely with deionized water acts as a control sample. In order to investigate the effect of an applied direct electric current upon the calcite distribution, 5 and $15 \mathrm{~V}$ electrical tensions were applied with electrodes placed apart by $5 \mathrm{~cm}$ which generate electric fields of 1 and $3 \mathrm{~V} / \mathrm{cm}$. The recorded current intensities ranged from 15 to $150 \mathrm{~mA}$ which is one order of magnitude lower than the hydraulic flow in terms of single charge flow. Results are presented with respect to the EC variation, $\mathrm{NH}^{4+}$ and $\mathrm{Ca}^{2+}$ concentration in outflows, as well as with respect to calcite distribution across the biocemented columns. Finally, Scanning Electron Microscopy observations on the texture of bio-cemented sand under EA-MICP illustrate the morphology and fabric of mineralized calcite and compared to that under conventional MICP.

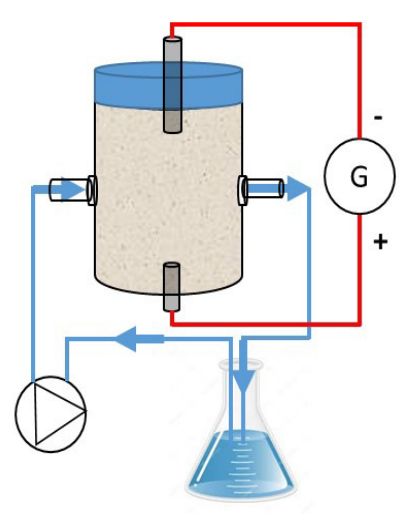

F : Calactate-Urea (0,25 M)

G : CaAcetate-Urea (0,5 M)

$0:$ No field

$1: 5 \mathrm{~V}-$ fixed voltage

$2: 15 \mathrm{~V}$ - fixed voltage

$3: 15 \mathrm{~V}$ - Alternating voltage



Fig. 1. Schematic representation of the setup used to induce EA-MICP in sand columns of $65 \mathrm{~mm}$ height to $45 \mathrm{~mm}$ diameter; blue arrows indicate inflow and outflow of reactive solutes and red arrows the applied current via a cathode and anode.

\section{Results}

\subsection{Monitoring of EA-MICP using $\mathrm{CaCl}_{2}$}

To monitor the EA-MICP process, electroconductivity (EC) measurements are used to provide insight into ion species production/consumption $\left(\mathrm{NH}_{4}^{+}\right.$and $\left.\mathrm{Ca}^{2+}\right)$. Differential electro-conductivities between the injected, parent solution and the collected outflow (Fig. 2a) show that under applied electrical current, values of EC recorded in the field-free case diverge from those of applied field case after 3 days. Hereafter, $\triangle \mathrm{EC}$ settles to approximately $+5 \mathrm{mS} / \mathrm{cm}$ in the field-free case, whereas in the case of both applied high $15 \mathrm{~V}$ and low $5 \mathrm{~V}$ electric potentials, no difference in $\mathrm{EC}$ is recorded. $\triangle \mathrm{EC}$ measurements are correlated to the ionic chromatography (IC) analyses which validate the depletion of $\mathrm{NH}_{4}{ }^{+}$with relevant concentrations reaching almost zero after 6 days in the applied field cases. Contrary, in the field-free case, $\mathrm{NH}_{4}{ }^{+}$production over time is captured (Fig. 2b). The $\mathrm{Ca}^{2+}$ concentration reaches that of the parent solution nominal concentration $(0.5 \mathrm{M})$ in the applied field cases. This shows that no reaction occurred, whereas $\mathrm{Ca}^{2+}$ consumption is observed in the field-free experiment. As for $\mathrm{Cl}^{-}$ions, the same trends are observed in every case with 
concentrations reaching the nominal parent solution concentration after 6 days.
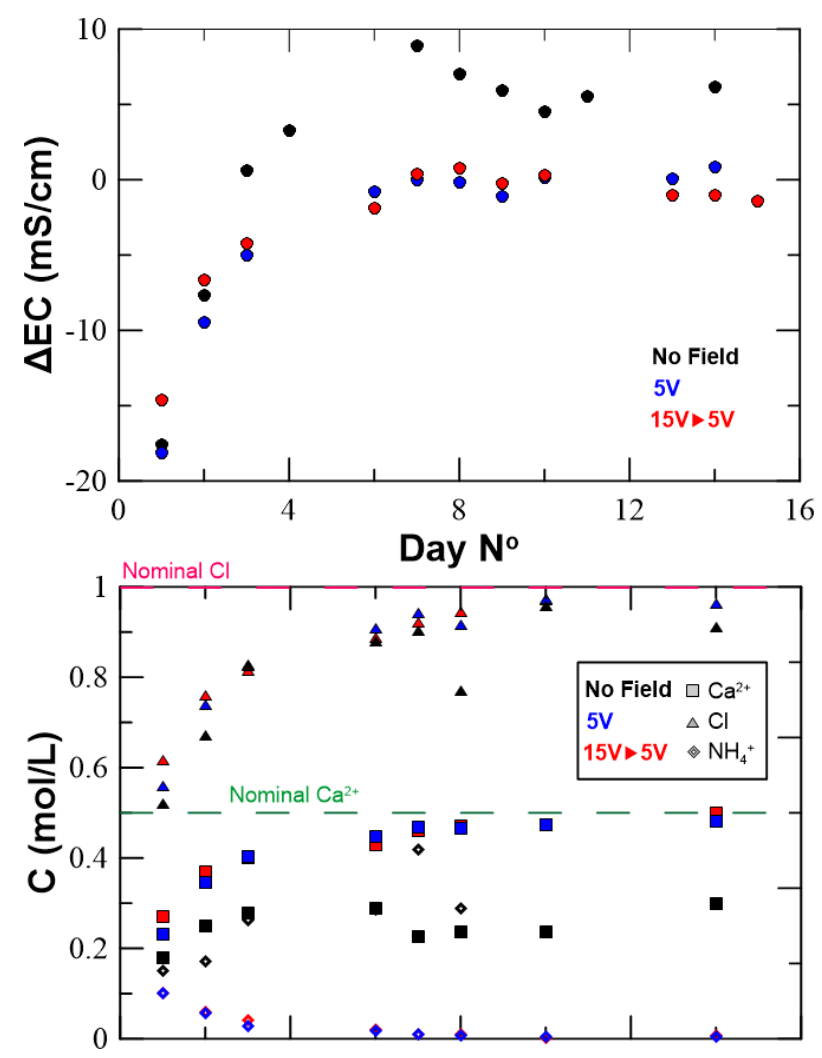

Fig. 2 Monitoring the MICP and EA-MICP processes by (a) Electric conductivity measurements and (b) IC elementary analyses.

\subsection{Sand column experiments on EA-MICP using $\mathrm{Ca}\left(\mathrm{C}_{2} \mathrm{H}_{3} \mathrm{O}_{2}\right)_{2}$ and $\mathrm{CaL}_{2}$}

Plots of the measured $\mathrm{NH}_{4}{ }^{+}$concentration in the outflow solutions show the clear relationship between the increased sample's resistivity with decreasing $\mathrm{NH}_{4}{ }^{+}$ content (Fig. 3a) with a linear correlation shown in Fig. 3b. Herein, the electrolysed chloride medium is responsible for the destruction of the bacteria cells, meaning no $\mathrm{NH}_{4}{ }^{+}$production occurs. Looking at the recorded resistivity of the samples treated with $\mathrm{CaL}_{2}$ and $\mathrm{Ca}\left(\mathrm{C}_{2} \mathrm{H}_{3} \mathrm{O}_{2}\right)_{2}$ under $5 \mathrm{~V}$ applied voltage (Fig. $3 \mathrm{c}$ and $3 \mathrm{~d}$ respectively), no relationship with the ammonium concentration can be extracted, meaning that electrochemical reactions take place, with $\mathrm{NH}_{4}^{+}$ production and $\mathrm{CaCO}_{3}$ mineralization resulting in quasinull $\Delta \mathrm{R}$.

The mineralized $\mathrm{CaCO}_{3}$ distribution is further illustrated in Fig. 4 for the samples produced using $\mathrm{CaL}_{2}$ and $\mathrm{Ca}\left(\mathrm{C}_{2} \mathrm{H}_{3} \mathrm{O}_{2}\right)_{2}$ under two applied voltages and compared to the case of no applied field.
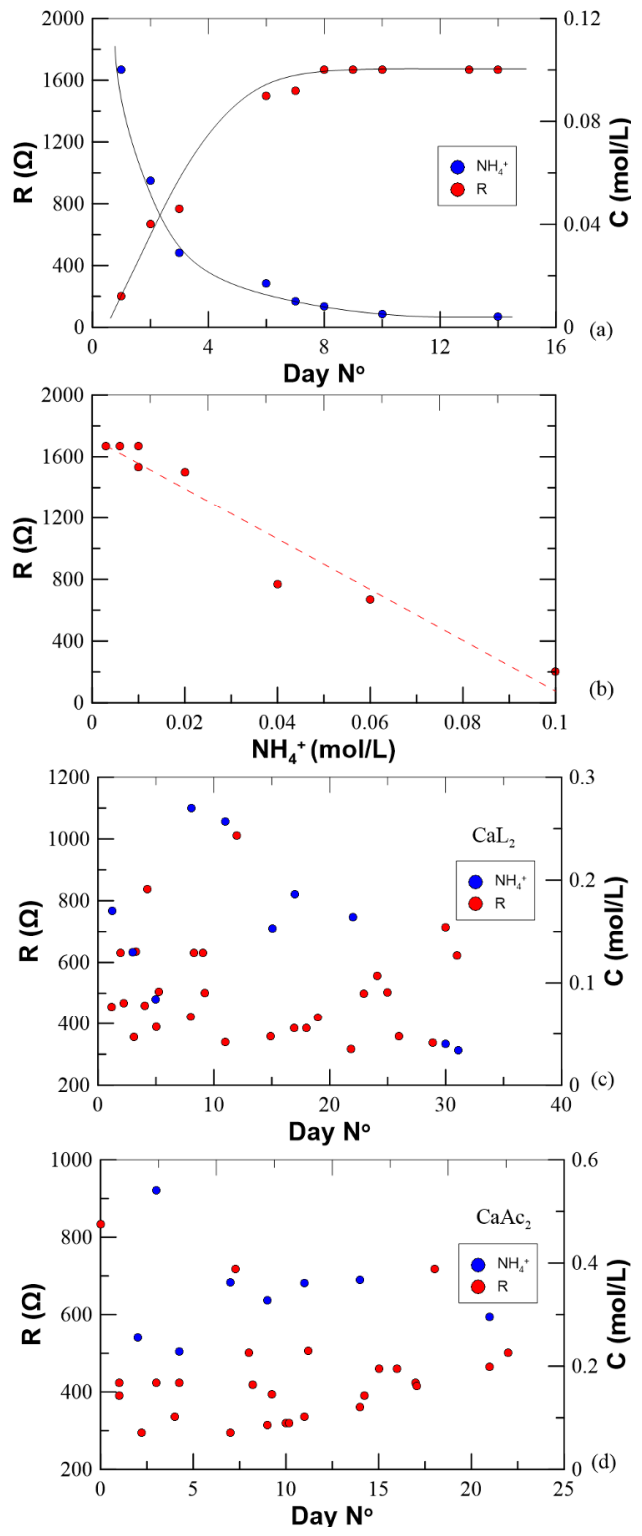

Fig. 3 Plots of the recorded electrical resistance with $\mathrm{NH}_{4}{ }^{+}$ content measurements over time periods of applied EA-MICP under $5 \mathrm{~V}$ applied voltage in: (a) calcium chloride with (b) the relationship between the sample's resistance and $\mathrm{NH}_{4}{ }^{+}$content, (c) calcium lactate and (d) calcium acetate media.

The $\mathrm{F}$ series $\left(\mathrm{CaL}_{2}\right.$ samples) in Fig. 4 shows that both $F_{0}$ (no field) and $F_{1}$ ( $5 \mathrm{~V}$ field of fixed polarity) samples display a similar trend with a maximum content observed in the middle section, where the reactive solution enters and flows out of the specimen. However, we observe that under an applied $5 \mathrm{~V}$ electric field, the distribution of $\mathrm{CaCO}_{3}$ shifts slightly towards higher contents both in the middle and towards the cathode end of the sample, where calcium is attracted. The same behaviour is observed for $F_{2}$ and $F_{3}$ samples which yield an extension of the cemented blocks towards the cathode with higher calcite contents than in the no field $\left(\mathrm{F}_{0}\right)$ case. The most homogenous distribution is yielded for $F_{3}$ sample, bio-cemented under alternating polarity of $15 \mathrm{~V}$. This much improved homogeneity across the sample's height is due to the successive electromigration of $\mathrm{Ca}^{2+}$ 
upwards or downwards, depending on the polarity of the applied electric field (see Fig. 1).

Table 2. Variation of $\mathrm{NH}_{4}{ }^{+}, \mathrm{Ca}^{2+}$ and $\mathrm{pH}$ for samples $\mathrm{F}$ and $\mathrm{G}$ during 17 batches of EA-MICP treatment.

\begin{tabular}{|c|c|c|c|c|c|c|c|}
\hline \multirow{2}{*}{ Sample } & \multicolumn{2}{|c|}{ Infiltrations 1-9 } & \multicolumn{2}{|c|}{ Infiltrations 10-17 } & \multicolumn{2}{|c|}{ Total } & \multirow{2}{*}{$\mathbf{p H}$} \\
\cline { 2 - 7 } & $\mathbf{N H}_{4}{ }^{+}$ & $\mathbf{C a}^{2+}$ & $\mathbf{N H}_{4}{ }^{+}$ & $\mathbf{C a}^{2+}$ & $\mathbf{N H}_{4}{ }^{+}$ & $\mathbf{C a}^{2+}$ & \\
\hline F0 & 0.29 & 0.18 & 0.37 & 0.16 & 0.33 & 0.17 & 7.9 \\
\hline F1 & 0.36 & 0.19 & 0.32 & 0.16 & 0.34 & 0.18 & 8.2 \\
\hline F2 & 0.30 & 0.17 & 0.25 & 0.14 & 0.28 & 0.15 & 8.1 \\
\hline F3 & 0.28 & 0.16 & 0.34 & 0.17 & 0.31 & 0.17 & 7.8 \\
\hline G0 & 0.14 & 0.11 & 0.37 & 0.14 & 0.24 & 0.12 & 7.7 \\
\hline G1 & 0.11 & 0.08 & 0.26 & 0.09 & 0.18 & 0.08 & 7.9 \\
\hline G2 & 0.16 & 0.09 & 0.25 & 0.09 & 0.20 & 0.09 & 7.8 \\
\hline G3 & 0.11 & 0.09 & 0.21 & 0.06 & 0.16 & 0.08 & 7.8 \\
\hline
\end{tabular}

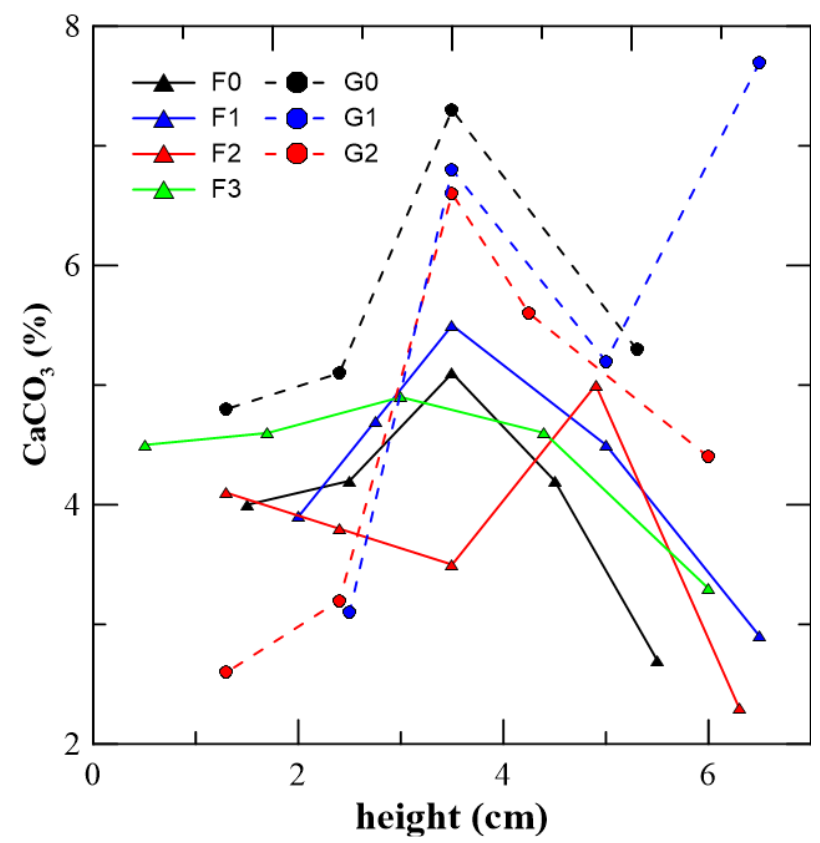

Fig. 4 Calcite content distributions across the bio-cemented columns' height under no-field ( 0 ) and three applied fields of $5,10,15 \mathrm{~V}$ for samples bio-cemented using $\mathrm{CaL}_{2}$ (F series) and $\mathrm{Ca}\left(\mathrm{C}_{2} \mathrm{H}_{3} \mathrm{O}_{2}\right)_{2}$ (G-series).

The efficiencies of produced $\mathrm{NH}_{4}^{+}$and that of depleted $\mathrm{Ca}^{2+}$ are shown in Table 2 and are expressed as the ratio of the measured $\mathrm{NH}_{4}{ }^{+}$in the outflow over the theoretical $\mathrm{NH}_{4}{ }^{+}$production, should urea had completely reacted. It should be noted that $\mathrm{Ca}\left(\mathrm{C}_{2} \mathrm{H}_{3} \mathrm{O}_{2}\right)_{2}$ treated samples were provided with $0.5 \mathrm{M}$ concentration compared to $0.25 \mathrm{M}$ for $\mathrm{CaL}_{2}$. Therefore, lower efficiency does not necessarily reflect lower calcite content. $\mathrm{G}$ samples reveal a different $\mathrm{CaCO}_{3}$ distribution pattern with the exception of $\mathrm{G}_{0}$ (field-free) case where the same variations are observed with respect to $F_{0}$ (field-free sample). $\mathrm{G}_{1}$ and $\mathrm{G}_{2}$ samples both display a local peak in calcite content in the middle section and a very strong depletion towards the bottom anode end. As far as the $G_{1}$ sample is concerned, the drop observed in calcite content in the middle is compensated by the increase towards the cathode, due to electromigration of $\mathrm{Ca}^{2+}$ ions which result in strong depletion in the anodic region. Thereby, supersaturation of the solution drops, preventing calcium carbonate precipitation. At $15 \mathrm{~V}$ applied voltage of fixed polarity, lower calcite content is yielded for the cathodic end while the rest of the distribution remains identical to that of $5 \mathrm{~V}$ fixed voltage. The sample G3 under alternating polarity did not yield sufficient bio-cementation and therefore its distribution is not shown in Fig. 4.

\subsection{Microstructural observations on EA-MICP "doped crystals"}

SEM observations on the texture and morphology of calcite binders which precipitated under applied electric field are carried-out and compared with the characteristics of field-free samples. Figs. 5 and 6 illustrate mineralized $\mathrm{CaCO}_{3}$ yielded using $\mathrm{CaL}_{2}$ and $\mathrm{Ca}\left(\mathrm{C}_{2} \mathrm{H}_{3} \mathrm{O}_{2}\right)_{2}$ as calcium sources respectively. Both figures compare the morphology of crystals which were produced via conventional MICP with those produced under EA-MICP. The selected observations highlighted the generally observed trend of minerals which grow larger planes, more stretched and elongated ones with less impurities or imperfections attributed to the presence of encapsulated cells.
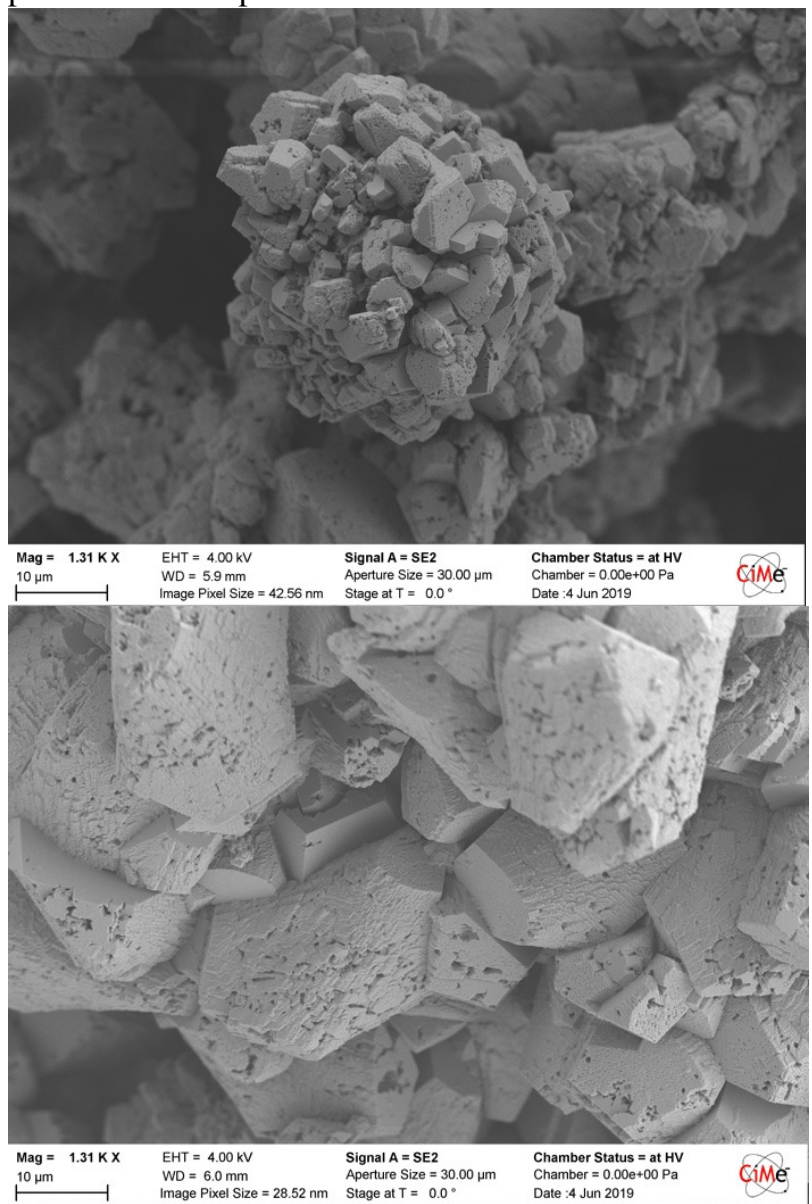

Fig. 5 SEM observations revealing calcite binders precipitated using $\mathrm{CaL}_{2}$ under no-field (top) and applied field of $5 \mathrm{~V}$ (bottom) for the same magnification

We postulate that this "doped" morphology of crystals is due to the formation of the crystalline lattice, composed of $\mathrm{Ca}^{2+}$ and $\mathrm{CO}_{3}{ }^{2-}$, under electric fields which results into a more hierarchical, or less random, distribution of ions and therefore to different nucleation 
forms. This finding implies that the effect of EA-MICP extends from influencing the calcite distribution and homogeneity across flow paths, as discussed in section 3.2, and impacts the microstructural and mechanical properties of the precipitated nuclei. Results on the mechanical behaviour of samples yielded under the various chemical and electrokinetic conditions will be the focus of a broader study, currently under development by the authors.
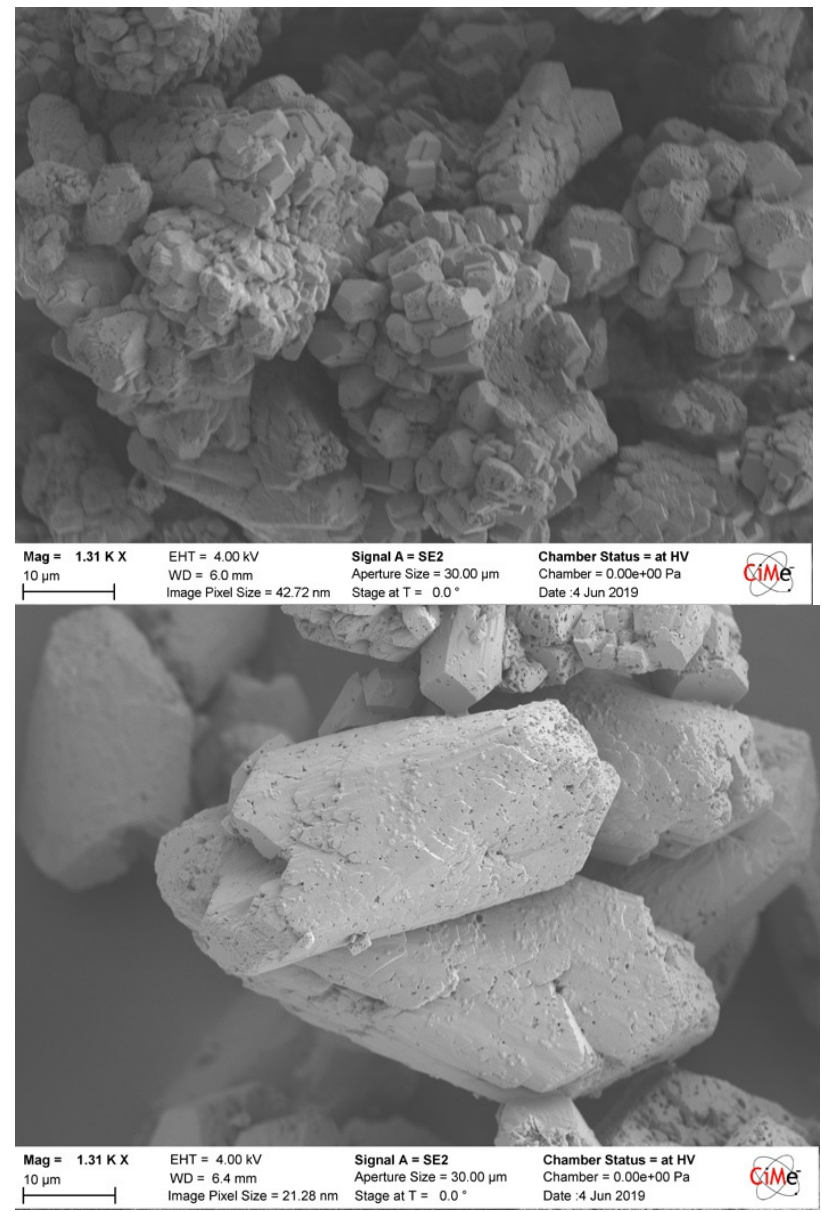

Fig. 6 SEM observations revealing calcite binders precipitated using $\mathrm{Ca}\left(\mathrm{C}_{2} \mathrm{H}_{3} \mathrm{O}_{2}\right)_{2}$ under no-field (top) and applied field of 5 $\mathrm{V}$ (bottom) for the same magnification

\section{Conclusions}

This work introduced the concept of EA-MICP and presented a series of benefits and limitations related to its application for soil bio-improvement. The complex reactive-transport phenomena involved in soil biocementation are herein understood as a bio-geo-chemical system which can be influenced significantly by the application of electric currents which induce electromigration of bacterial cells and dissolved solutes. Results present the positive effect of applied electric fields of varying force and polarity on the distribution of calcite binders when these precipitate using $\mathrm{Ca}\left(\mathrm{C}_{2} \mathrm{H}_{3} \mathrm{O}_{2}\right)_{2}$ and $\mathrm{CaL}_{2}$ as $\mathrm{Ca}^{2+}$ sources. Contrary, EA-MICP has a detrimental effect when using $\mathrm{CaCl}_{2}$ for inducing bio- cementation due to the strong acidic front produced. An interesting finding is that application of electric fields results into enhanced morphologies for the mineralized binders, which grow and stretch their planes following more hierarchical patterns. This beneficial form of "doped" crystals is expected to influence the engineering properties of binders and that of the bio-cemented geomaterial. The work overall introduces a new concept for MICP which sets new ground for developments and optimization in the field of soil bio-improvement.

\section{Acknowledgements}

This work has received funding from the European Research Council (ERC) under the European Union's Horizon 2020 research and innovation programme (grant agreement No 788587). Authors express their thanks to Mr. Ray Harran for contributing in the SEM observations.

\section{References}

1. Cardoso, R. and Santos, J.N., 2013. Experimental study on the use of electroosmosis for accelerating the consolidation of clays under increasing vertical stress. In Poromechanics V: Proceedings of the Fifth Biot Conference on Poromechanics (pp. 1515-1523

2. Citeau, M., Larue, O., \& Vorobiev, E. (2015). Electric (Electro/Dielectro-Phoretic)-Force Field Assisted Separators. In Progress in Filtration and Separation (pp. 325-397). London: Elsevier.

3. Fukuzaki, S., 2006. Mechanisms of actions of sodium hypochlorite in cleaning and disinfection processes. Biocontrol science, 11(4), pp.147-157.

4. Gingine, V. and Cardoso, R., 2019. Monitoring of electrokinetic treatment of landfill leachatecontaminated clay in Portugal. Environmental Geotechnics, pp.1-14.

5. Keykha, H. A., Huat, B. B., Asadi, A., \& Kawasaki, S. (2012). Electro-Biogrouting and Its Challenges. International Journal of Electrochemical Science, 7 1196-1204.

6. Keykha, H. A., Huat, B. B., Asadi, A., Zareian, M., \& Kawasaki, S. (2015). Electrokinetic properties of pasteurii and aquimarina bacteria. Environmental Geotechnics, 2 EG3 181-188.

7. Keykha, H. A., Huat, B. B., \& Asadi, A. (2014). Electrokinetic Stabilization of Soft Soil Using Carbonate-Producing Bacteria. Geotechnical and Geological Engineering, 32:739-747.

8. Keykha, H. A., \& Asadi, A. (2017). Solar Powered Electro-Bio-Stabilization of Soil with Ammonium Pollution Prevention System. Advances in Civil Engineering Materials, 6.1. 360-371

9. Kim, S.-H., Han, H.-Y., Lee, Y.-J., Kim, C. W., \& Yang, J.-W. (2010). Effect of electrokinetic remediation on indigenous microbial activity and community within diesel contaminated soil. Science of the Total Environment, 408 3162-3168.

10. Terzis, D. and Laloui, L., 2019a. A decade of progress and turning points in the understanding of 
bio-improved soils: A review. Geomechanics for Energy and the Environment, 19, p.100116.

11. Terzis, D. and Laloui, L., 2019b. Cell-free soil biocementation with strength, dilatancy and fabric characterization. Acta Geotechnica, 14(3), pp.639656. 